\title{
AS PLATAFORMAS DIGITAIS UTILIZADAS NO AVA DAS IES QUE OFERTAM O CURSO DE GRADUAÇÃO TECNOLÓGICA EM ANÁLISE E DESENVOLVIMENTO DE SISTEMAS (ADS), NA REGIÃO METROPOLITANA DE FLORIANÓPOLIS (RMF)
}

\author{
FLORIANÓPOLIS/SC JULHO/2018
}

\author{
José Carlos Mariano do Carmo - FAEL - mariano.carmo4@gmail.com \\ Luciano José Kogut - SENAC - ljkogut1@gmail.com \\ Leandro Pieper Nunes - SENAC - Ipiepernunes@gmail.com \\ Augusto Ferronato Lima - SENAC - ferronato.guto@gmail.com
}

Tipo: Investigação Científica (IC)

Natureza: Descrição de Projeto em Andamento

Categoria: Métodos e Tecnologias

Setor Educacional: EDUCAÇÃO SUPERIOR

\begin{abstract}
RESUMO
A Educação a Distância vem apresentando aumento substancial na oferta de cursos e na procura por parte de novos alunos, embora seja encarado com certo preconceito por algumas organizações e no próprio mercado de trabalho. A metodologia de pesquisa utilizada é a qualitativa em relação às características do curso, exploratória em relação aos meios pesquisados e comparativa ao trabalhar os dados disponíveis e os resultados obtidos. O objetivo deste artigo é efetuar um recorte sobre particularidades dessa modalidade de ensino, no curso Análise e Desenvolvimento de Sistemas (ADS) no entorno da capital catarinense, mais especificamente na Região Metropolitana de Florianópolis (RMF) que totalizam vinte e seis Instituições de Ensino Superior ofertantes do curso. Apresentam-se as modalidades EaD semipresencial (metodologia híbrida) e integral à distância, indicando o Ambiente Virtual de Aprendizagem (AVA) e plataformas mais utilizadas pelas Instituições de Ensino Superior (IES), contribuindo para reflexão do discente como protagonista da aprendizagem e parte da legislação pertinente em relação à área do curso. Além disso, o artigo apresenta informações essenciais do objeto de pesquisa, incluindo: informação da carga horária disponível no e-MEC e nos sites institucionais, a possibilidade de uso de dispositivos móveis e, também, a integração desses por meio de aplicativos (Apps) com o AVA e o sistema acadêmico. Nos resultados finais, recomenda-se o compartilhamento de informações entre as plataformas e outras particularidades.
\end{abstract}

Palavras-chave: Educação a Distância. Curso semipresencial. Instituições de Ensino Superior (IES). Ambiente Virtual de Aprendizagem (AVA). Plataformas Digitais.

\section{AGRADECIMENTOS}

AGRADECEMOS ÀS INSTITUIÇÕES (FAEL E SENAC), AOS DOCENTES E AOS DISCENTES ENVOLVIDOS NESTA PESQUISA CIENTÍFICA. 


\title{
1 INTRODUÇÃO
}

Na RMF $^{[1]}$ o uso de ferramentas inovadoras já está com ampla divulgação, sabendo-se que as empresas de tecnologia e desenvolvimento buscam cada vez mais profissionais capacitados e preparados para romper paradigmas, não só em relação à programação, ao uso de novas linguagens computacionais, aos processos de desenvolvimento de softwares, à base tecnológica utilizada durante a formação acadêmica e, também, como esta foi planejada e distribuída pela IES na prática pedagógica.

Considerando o cenário acima, faz-se importante ter como ponto de partida a verificação da grade curricular ${ }^{[2]}$ ofertada nos cursos de ADS das IES na RMF, havendo necessidade de diferenciar os cursos presenciais dos cursos a distância, especialmente no que tange ao uso de ferramentas que auxiliem os discentes na absorção dos conteúdos lecionados em salas de aulas virtuais, além de facilitar o acompanhamento docente em relação às turmas que estejam trabalhando o conteúdo acadêmico, parcialmente ou integralmente na modalidade EaD.

Além da modalidade de ensino, outro ponto importante a se observar são as diferenças entre os tipos de graduações ofertadas e os níveis de cada grau, pois de acordo com a Portaria Normativa no 40, de 12 de dezembro de 2007, do Ministério da Educação, temos as seguintes diferenças entre os tipos de cursos e o grau:

\footnotetext{
Graduação - cursos superiores que conferem diplomas, abertos a candidatos que tenham concluído o ensino médio ou equivalente e tenham sido classificados em processo seletivo, conferindo os graus de Bacharelado, Licenciatura ou Tecnologia.
}

\begin{abstract}
Bacharelado - curso superior generalista, de formação científica ou humanística, que confere ao diplomado competências em determinado campo do saber para o exercício de atividade profissional, acadêmica e cultural, com o grau de bacharel.
\end{abstract}

\footnotetext{
Licenciatura - curso superior que confere ao diplomado competências para atuar como professor na educação básica, com o grau de licenciado.

Tecnologia - cursos superiores de formação especializada em áreas científicas e tecnológicas, que conferem ao diplomado competências para atuar em áreas profissionais específicas, caracterizadas por eixos tecnológicos, com o grau de tecnólogo. (BRASIL, 2007, p. 43, grifos nossos).
}

As diferenças apresentadas apontam, num primeiro momento, para o fato de que não há nenhuma distinção entre um curso superior tecnológico e um curso de graduação mais generalista, para fins de titulação. Além disso, o Curso Superior em Tecnologia (CST) pode ser integralizado de forma mais rápida, facilitando o acesso de especialistas com qualificação no mercado de trabalho. 
Quanto à carga horária dos cursos de graduação, os limites mínimos e as regulamentações das Diretrizes Nacionais Curriculares da área de computação (BRASIL, 2016a) também são apresentadas por Kogut et al (2017), sendo que o planejamento mínimo da grade curricular dos cursos de bacharelado e das engenharias ligadas a esta área, variam entre 3.200 horas e 2.000 horas, com quantidade mínima de 8 semestres para os bacharelados, engenharias e licenciaturas ligadas à computação, enquanto o tecnólogo pode ser integralizado em 5 semestres, sendo que tal agilidade se dá "[...] por se tratar da especificidade do curso e o enfoque dado às necessidades do mercado de trabalho [...]" (KOGUT et al, 2017, p. 3).

Segundo Espíndola (2016, p. 6), o AVA pode ser entendido como "[...] um local virtual onde são disponibilizadas ferramentas. que permite o acesso a um curso ou disciplina [...]", para que o ambiente presencial e virtual favoreçam a formação e o acompanhamento dos alunos, por meio do acesso de qualquer lugar que ofereça acesso à internet e no momento desejado pelo discente.

As informações até aqui mencionadas indicam a importância que o alunado deve ter ao escolher o tipo de curso para graduação, possíveis variações da modalidade de ensino EaD, o AVA utilizado pelas IES e demais abordagens que o artigo traz.

\section{OBJETIVOS}

Para auxiliar a busca de respostas sobre as dúvidas já relatadas, propõe-se neste artigo:

- Identificar as entidades que ofertam o curso de graduação tecnológica em ADS na RMF;

- Identificar a modalidade de ensino ofertada por cada IES para o curso em questão;

- Apresentar a carga horária da grade curricular proposta;

- Identificar o(s) AVA(s) utilizado(s) pelo público envolvido.

\section{REFERENCIAL TEÓRICO}

A EaD tem crescido consideravelmente no Brasil, havendo necessidade de que as IES procurem plataformas que possam atender aos alunos, seja de forma passiva, quando 0 aluno solicita que sejam dirimidas dúvidas ao tutor ou, ainda, na forma ativa, em que há encontros virtuais ou presenciais entre o tutor e os discentes. Em tais encontros, não se trata, em tese, dos alunos utilizarem os conteúdos da aprendizagem, mas de interagirem com os colegas e com o corpo docente, numa postura de ser o sujeito que aprende e 
questiona os conteúdos a serem apreendidos, dentro das propostas de Paulo Freire, no que tange à autonomia e de Vygotsky no que tange à aprendizagem por meio da interação com os colegas e com o tutor-docente.

Nesta linha de raciocínio, dentro da EaD, chama-se de curso semipresencial, aqueles que oferecem encontros entre o corpo discente e os tutores apenas para avaliações e/ou consulta; e de metodologia híbrida, uma tendência inovadora entre encontros virtuais e presenciais, como sendo, tais encontros, os que os alunos passam a ser protagonistas do processo de ensino e de aprendizagem, também chamada de sala de aula invertida.

\footnotetext{
A primeira vez que se tem notícia de algo que possa remeter à Flipped Classroom foi no início de 1990, [...]. Mas pode-se afirmar que quem revolucionou o processo foi Salman Khan em 2004, nos Estados Unidos, quando começou a gravar vídeos para tutoria, após o sucesso dos vídeos criou a Kahn Academy [...] tornou-se sinônimo de sala de aula invertida, [...] mas deve-se lembrar que os vídeos são apenas uma forma da estratégia de se inverter a sala. (BATISTA JR., 2017, p. 2-3).
}

Em que pese nomenclaturas diferenciadas e novas plataformas digitais, Paulo Freire faz considerações que deveriam integrar também a EaD:

\footnotetext{
Desta maneira, o educador já não é o que apenas educa, mas o que, enquanto educa, é educado, em diálogo com o educando que, ao ser educado, também educa. Ambos, assim, se tornam sujeitos do processo em que crescem juntos [...]. (FREIRE, 2005, p. 79).
}

Estreitar o relacionamento entre docentes e discentes no ambiente presencial é procedimento comum, ocasionando até mesmo rupturas de paradigmas em algumas estruturas acadêmicas e pedagógicas conservacionistas. Já na educação a distância, dialogar e envolver-se com os alunos, para além da orientação do corpo discente, tornase um desafio constante quando tratamos de diferentes públicos e AVAs utilizados pelas IES, pois o tutor "[...] é também o animador do processo, aquele que estabelece vínculo [...] instigando-os a participar das atividades presenciais e dos encontros virtuais [...]". (GONÇALVES et al, 2002, p. 64).

Em contrapartida, o viés do corpo discente está mais orientado à realização de atividades propostas, às participações direcionadas em fóruns de discussão e, para alguns integrantes dessa modalidade de ensino, vale apenas as atividades e avaliações presenciais obrigatórias de alguns cursos ou as demais atividades que algumas instituições exigem, mesmo tendo ciência de que: "[...] partilhar experiências e refletir em conjunto, mesmo a distância, é fundamental para a construção e a socialização do conhecimento". (GONÇALVES et al, 2002, p. 64). 


\section{PROCEDIMENTOS METODOLÓGICOS}

Como o objetivo deste artigo é apresentar parte do resultado de uma pesquisa, para o curso analisado, passa a ser primordial sabermos quais são as plataformas digitais e os AVAs mais utilizadas pelas IES. Para tanto, a metodologia proposta é a pesquisa nos sites das Instituições, bem como contato telefônico ou por e-mail. Nestas duas últimas maneiras, ficamos na dependência de contatar alguém vinculado ao curso das IES que pudesse responder a tais questionamentos.

Tendo em vista o exposto por Cervo, Bervian e Da Silva (2007, p. 63) e por tratar de uma pesquisa exploratória em que "[...] tais estudos têm por objetivo familiarizar-se com o fenômeno ou obter uma nova percepção dele e descobrir novas ideias" e para delimitar o campo geográfico, aborda-se as entidades que ofertam o curso de graduação tecnológica em ADS na RMF, considerando a legislação imposta pela Lei Complementar nํ 636 de 9 de Setembro de 2014, no seu artigo $1^{\circ}$ e parágrafo $1^{\circ}$, que relaciona a abrangência dos municípios do entorno da capital catarinense, além da identificação de características básicas deste curso, tendo por base os dados do site oficial do MEC (eMEC) e das informações constantes nas páginas institucionais, a fim de que sejam identificadas quais as plataformas digitais são utilizadas pelas IES no ambiente de tutoria EaD ou semipresencial e as modalidades de ensino ofertadas. Em alguns casos, na impossibilidade em obter tais informações, optamos por contato telefônico.

Um dos problemas verificados foi a dificuldade de falar com o Coordenador do Curso ou da área, sendo que muitas vezes a IES possui, na RMF, apenas um polo de apoio e a sede institucional está localizada em outra cidade. Além das dificuldades no atendimento, revelando desconhecimento técnico e detalhes quanto ao tema solicitado, muitas IES deixam este tipo de informação de maneira não muito clara e respondem ter plataformas digitais de AVAs próprias, quando provavelmente utilizam de sistemas já conhecidos, como o Moodle ou o Blackboard com modelos e templates próprios e adaptados às suas IES.

Infelizmente, quanto à plataforma digital, não temos como afirmar com os dados obtidos e com a certeza que gostaríamos, quais são os ambientes e plataformas utilizados, acreditando nas respostas recebidas e tabulando as informações com o coletado na pesquisa e no período compreendido entre fevereiro e abril de 2018.

\section{APRESENTAÇÃO E DISCUSSÃO DOS RESULTADOS}

Para mitigar as dúvidas sobre o tipo de curso ofertado, as modalidades de ensino 
utilizadas pelas IES e a carga horária constante na matriz do curso, apresenta-se a tabulação abaixo, observando que para cada IES foram identificados os tipos de cursos ofertados, com suas particularidades em caso de divergências entre o site do e-MEC e o site do curso, além das informações levantadas pela metodologia aplicada.

Abaixo os detalhes da coleta de dados.

Figura 1 - Relação de instituições de ensino que oferecem o curso de ADS na RMF e suas características

\begin{tabular}{|c|c|c|c|}
\hline Nome da IES & $\begin{array}{l}\text { Modalidade de } \\
\text { Ensino }\end{array}$ & Carga Horária & AVA Utilizado \\
\hline 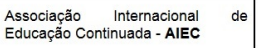 & EaD $100 \%$ & $\begin{array}{l}\text { 2010h e-MEC } \\
\text { 2100h site IES }\end{array}$ & $\begin{array}{l}\text { Proprio, em Web com uso } \\
\text { em Mobile }\end{array}$ \\
\hline $\begin{array}{l}\text { Centro Universitario Claretiano } \\
\text { CEUCLAR }\end{array}$ & $\operatorname{EaD} 100 \%$ & $\begin{array}{l}\text { 2000he-MEC } \\
2000 \text { h site IES }\end{array}$ & $\begin{array}{l}\text { Próprio, em Web com uso } \\
\text { em Mobile }\end{array}$ \\
\hline $\begin{array}{l}\text { Centro Universitário da Grande } \\
\text { Dourados-UNIGRAN }\end{array}$ & $\operatorname{EaD} 100 \%$ & $\begin{array}{l}\text { 2000h Q-MEC } \\
\text { 2180h site IES }\end{array}$ & $\begin{array}{l}\text { Próprio, em Web com App } \\
\text { Integrado e Parceria Google } \\
\text { for Education }\end{array}$ \\
\hline $\begin{array}{l}\text { Centro Universitario de Maringa } \\
\text { UNICESUMAR }\end{array}$ & EaD $100 \%$ & $\begin{array}{l}\text { 2200h e-MEC } \\
\text { 2200h site IES }\end{array}$ & $\begin{array}{l}\text { Proprio, em Web com uso } \\
\text { em Mobile }\end{array}$ \\
\hline $\begin{array}{l}\text { Centro Universitário Estácio de } \\
\text { Ribeirão Preto - UNISEB }\end{array}$ & $\operatorname{EaD} 100 \%$ & $\begin{array}{l}2568 \mathrm{~h} \text {-MEC } \\
1477 \mathrm{~h} \text { site IES }\end{array}$ & $\begin{array}{l}\text { Próprio, em Web com uso } \\
\text { em Mobile }\end{array}$ \\
\hline $\begin{array}{l}\text { Centro Universitário Internacional - } \\
\text { UNINTER }\end{array}$ & $\operatorname{EaD} 100 \%$ & $\begin{array}{l}\text { 2128h }- \text {-MEC } \\
\text { 2056h site IES }\end{array}$ & Próprio, em Web \\
\hline $\begin{array}{l}\text { Centro Universitário Leonardo Da } \\
\text { Vinci - UNIASSELVI }\end{array}$ & $\begin{array}{l}\text { EaD } 100 \% \text { com } \\
\text { tutoria no polo }\end{array}$ & \begin{tabular}{|l} 
2520h e-MEC \\
NR site IES
\end{tabular} & $\begin{array}{l}\text { Proprio, em Web com uso } \\
\text { em Mobile }\end{array}$ \\
\hline $\begin{array}{l}\text { Centro Universitário Mauricio de } \\
\text { Nassau - UNINASSAU }\end{array}$ & EaD $100 \%$ & $\begin{array}{l}\text { 2100h e-MEC } \\
\text { 2040h site IES }\end{array}$ & $\begin{array}{l}\text { Microsoft OneDrive, em Web } \\
\text { com uso em Mobile }\end{array}$ \\
\hline Centro Universitário Sociesc & $\begin{array}{l}\text { Consta e-MEC } \\
\text { como EaD }\end{array}$ & \begin{tabular}{|l|}
$2000 \mathrm{~h}$ e-MEC \\
$2448 \mathrm{~h}$ resol. IES
\end{tabular} & NR não oferta na RMF \\
\hline $\begin{array}{l}\text { Complexo de Ensino Superior de } \\
\text { Santa Catarina - CESUSC }\end{array}$ & \begin{tabular}{|l} 
Presencial \\
\end{tabular} & $\begin{array}{l}2400 \mathrm{~h} \text {-MEC } \\
2400 \mathrm{~h} \text { site IES }\end{array}$ & $\begin{array}{l}\text { Próprio, em Web com App } \\
\text { Integrado }\end{array}$ \\
\hline $\begin{array}{l}\text { Faculdade Educacional da Lapa } \\
\text { FAEL }\end{array}$ & $\operatorname{EaD} 100 \%$ & $\begin{array}{l}2100 \mathrm{~h} \mathrm{e}-\mathrm{MEC} \\
2200 \mathrm{~h} \text { site IES }\end{array}$ & Moodle, em Web \\
\hline $\begin{array}{l}\text { Serviço Nacional de Aprendizagem } \\
\text { Comercial - SENAC Florianópolis }\end{array}$ & \begin{tabular}{|l} 
Presencial \\
\end{tabular} & $\begin{array}{l}\text { 2100h e-MEC } \\
2100 \mathrm{~h} \text { site IES }\end{array}$ & $\begin{array}{l}\text { Blackboard e Parceria } \\
\text { Google for Education }\end{array}$ \\
\hline $\begin{array}{l}\text { Servico Nacional de Aprendizagem } \\
\text { Industrial - SENAI }\end{array}$ & Presencial & $\begin{array}{l}\text { 2440h } \mathrm{e}-\mathrm{MEC} \\
2410 \mathrm{~h} \mathrm{sit} \text { IES }\end{array}$ & $\begin{array}{l}\text { Moodle, em Web e Parceria } \\
\text { Google for Education }\end{array}$ \\
\hline
\end{tabular}

\begin{tabular}{|c|c|c|c|}
\hline Nome da IES & $\begin{array}{l}\text { Modalidade de } \\
\text { Ensino }\end{array}$ & Carga Horária & AVA Utilizado \\
\hline $\begin{array}{l}\text { Universidade Anhembi Morumbi } \\
\text { UAM | LAUREATE }\end{array}$ & EaD 100\% & $\begin{array}{l}2135 \mathrm{~h} \text { e-MEC } \\
2129 \mathrm{~h} \text { site IES }\end{array}$ & Moodle, em Web \\
\hline $\begin{array}{l}\text { Universidade da Amazônia } \\
\text { UNAMA | UNIVERITAS }\end{array}$ & $\begin{array}{l}\text { Consta 日-MEC } \\
\text { como EaD e não } \\
\text { oferta na RMF }\end{array}$ & $\begin{array}{l}2100 \mathrm{~h} \text {-MECC } \\
\text { NR site IES }\end{array}$ & $\begin{array}{l}\text { Microsoft OneDrive, em Web } \\
\text { com uso em Mobile }\end{array}$ \\
\hline Universidade de Franca - UNIFRAN & $\mathrm{EaD} 100 \%$ & $\begin{array}{l}\text { 2000h e-MEC } \\
\text { NR site IES }\end{array}$ & $\begin{array}{l}\text { Blackboard, finaliza em } \\
\text { quatro semestres }\end{array}$ \\
\hline $\begin{array}{l}\text { Universidade do Sul de Santa } \\
\text { Catarina-UNISUL }\end{array}$ & Presencial & $\begin{array}{l}\text { 2040h e-MEC } \\
\text { 2040h site IES }\end{array}$ & Moodle, em Web \\
\hline $\begin{array}{l}\text { Universidade do Vale dos Sinos - } \\
\text { UNISINOS }\end{array}$ & $\mathrm{EaD} 100 \%$ & $\begin{array}{l}\text { 2130h e-MEC } \\
\text { NR site IES }\end{array}$ & Moodle, em Web \\
\hline Universidade Estácio de Sá & $\begin{array}{l}\text { EaD } 100 \% \\
\text { Semipresencial }\end{array}$ & $\begin{array}{l}2312 \mathrm{~h} \text { e-MEC } \\
1477 \mathrm{~h} \mathrm{site} \mathrm{IES}\end{array}$ & 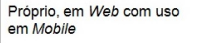 \\
\hline Universidade Paulista - UNIP & EaD 100\% & $\begin{array}{l}\text { 2280h e-MEC } \\
\text { 2280h site IES }\end{array}$ & $\begin{array}{l}\text { Próprio, em Web com App } \\
\text { Integrado e Recursos } \\
\text { Adicionais }\end{array}$ \\
\hline $\begin{array}{l}\text { Universidade Universo Veritas } \\
\text { UNIVERITAS }\end{array}$ & $\begin{array}{l}\text { EaD } 100 \% \\
\text { Semipresencial }\end{array}$ & $\begin{array}{l}\text { 2000h e-MEC } \\
2100 \mathrm{~h} \mathrm{site} \mathrm{IES}\end{array}$ & $\begin{array}{l}\text { Microsoft OneDrive, em Web } \\
\text { com uso em Mobile }\end{array}$ \\
\hline $\begin{array}{l}\text { Serviço Nacional de Aprendizagem } \\
\text { Comercial - SENAC Palhoça }\end{array}$ & Presencial & $\begin{array}{l}2100 \mathrm{e} \text {-MEC } \\
2100 \mathrm{~h} \mathrm{site} \mathrm{IES}\end{array}$ & $\begin{array}{l}\begin{array}{l}\text { Parceria Google for } \\
\text { Education }\end{array}\end{array}$ \\
\hline Universidade Pitágoras - UNOPAR & $\mathrm{EaD} 100 \%$ & $\begin{array}{l}\text { 2320h e-MEC } \\
2220 \mathrm{~h} \mathrm{site} \mathrm{IES}\end{array}$ & $\begin{array}{l}\text { Pröprio, em Web com } \\
\text { integração Mobille e } \\
\text { Recursos Adicionais }\end{array}$ \\
\hline Universidade Positivo - UP & $\begin{array}{l}\text { Consta e-MEC } \\
\text { como EaD e não } \\
\text { oferta na RMF }\end{array}$ & $\begin{array}{l}\text { 2000h Q-MEC } \\
\text { NR site IES }\end{array}$ & $\begin{array}{l}\text { Próprio, em Web com App } \\
\text { Integrado }\end{array}$ \\
\hline $\begin{array}{l}\text { Centro Universitario Municipal de } \\
\text { Săo José - USJ }\end{array}$ & Presencial & $\begin{array}{l}\text { 2160n e-MEC } \\
\text { NR site IES }\end{array}$ & Moodle, em Web \\
\hline $\begin{array}{l}\text { Faculdade Municipal da Palhoça } \\
\text { FMP }\end{array}$ & $\begin{array}{l}\text { Consta docs na } \\
\text { Secretaria de } \\
\text { Educaçăo }\end{array}$ & $\begin{array}{l}\text { NR G-MEC } \\
\text { NR Secretaria } \\
\text { NR site IES }\end{array}$ & $\begin{array}{l}\text { NR e informaç̃̂es indicam } \\
\text { como Presencial }\end{array}$ \\
\hline
\end{tabular}

Fonte: (e-MEC, 2018) e Dados da Pesquisa (2018).

O total de instituições pesquisadas que estão divulgando ou ofertando o curso de ADS na RMF e/ou com tramitação de documentos para autorização, chega a vinte e seis IES, sendo que $61,54 \%$ oferecem o curso integral em EaD, 23,08\% disponibilizam o curso presencialmente, apenas 7,69\% oferecem o curso parcialmente EaD (semipresencial) e $15,38 \%$ ainda não finalizaram o processo de autorização do curso ou já estariam com os atos autorizativos, mas não começaram a ofertar o curso pelos sites institucionais.

Há dezesseis instituições que oferecem a modalidade de ensino EaD 100\%. No caso deste tipo de oferta, observamos que quase a totalidade de IES exigem no mínimo dois encontros presenciais por módulo e/ou semestre letivos, para que sejam aplicadas as avaliações disciplinares presenciais. Apenas duas instituições disponibilizam a modalidade semipresencial para o curso de ADS. Acreditamos que a baixa ocorrência está vinculada à localização do município sede da IES, pois a maioria de instituições que ofertam ADS em EaD possuem a sede institucional fora da RMF. 
Há sete instituições que executam o curso na modalidade presencial, sendo que para este caso uma IES está com documentação para autorização junto ao órgão regulador de sua abrangência. Destaca-se para esta modalidade que a legislação atual possibilita a execução de até $20 \%$ da carga horária, com seus conteúdos abordados pelo AVA ou outro tipo de plataforma de aprendizagem.

Identificou-se que doze IES utilizam pelo menos um tipo de AVA ou plataforma digital já conhecida pelo público educacional, a exemplo de seis instituições usuárias do Moodle, três que utilizam o Blackboard, quatro delas que já formalizaram parceria com o Google for Education e três que se beneficiam dos recursos da plataforma em nuvem da Microsoft OneDrive.

Existem ainda, doze instituições que utilizam AVAs próprios, com variações entre a utilização no ambiente Web exclusivamente, ou em Web com adaptabilidade para dispositivos móveis (Mobile). Há também uso de ambiente Web com integração por aplicativo acadêmico ( $A p p$ ) e outras que indicam a utilização de recursos não abordados pelo questionário elaborado, a exemplo de transmissão via satélite e/ou canal do Youtube e ainda gravação de vídeos aulas com viés pedagógico para utilizar a metodologia sala de aula invertida (Flipped Classroom).

Vale ressaltar que existem IES na RMF trabalhando com duas ou até três plataformas e/ou ambientes diferentes pesquisados e apenas oito delas deixam estas informações de modo bem explícito e de fácil acesso ao público envolvido.

Conforme os dados pesquisado, duas instituições não responderam às questões sobre uso de AVA ou plataformas (NR), pois segundo informações dos colaboradores contactados, ambas estão com processo de autorização em andamento junto ao MEC e/ou Secretaria Estadual de Educação e ainda uma dessas não cadastrou os detalhes no site do curso e a outra já divulga a execução do curso como sendo "em breve", estando sem os detalhes acerca da grade curricular, mantendo documento comprobatório de autorização e que não prejudica a análise aqui realizada.

Uma situação preocupante identificada está relacionada à carga horária do curso, pois conforme citado anteriormente, algumas IES contemplam a informação de carga horária mínima estipulada pelo CNCST (mínimo de 2000h), mas nos sites institucionais a carga horária está maior que a cadastrada no e-MEC. Este fato não é tão preocupante, considerando o que ocorre em nove instituições pesquisadas, que informam pelo site uma carga horária "menor" do que a cadastrada e, pior, em dois casos a carga horária "mínima" não é oferecida, conforme site das IES. 
Sobre a carga horária constante nos sites das IES, percebemos que algumas delas mantêm inconsistência entre o que está informado como conteúdo disciplinar e atividades complementares. Além disso, outro ponto de destaque, remete à ausência de detalhes de quantas horas ou horas/aula são constituídas as disciplinas e/ou módulos, principalmente nas modalidades $\mathrm{EaD}$ ou em suas variações, pois se na grade curricular inexiste o total contemplado por disciplina, fica impossível totalizar a carga horária de algumas IES que ofertam essa modalidade. O mais curioso que observamos foi a existência de uma única IES ofertando 2000h de carga horária total de curso, conforme e-MEC, sem indicar no site institucional como as disciplinas são divididas e sem os detalhes de carga horária disciplinar.

A respeito da modalidade de ensino, sugere-se que as instituições que ofertam os cursos semipresenciais, híbridos ou parcialmente EaD, padronizem as páginas institucionais e forneçam explicações claras sobre as variações do ensino EaD, a exemplo de duas instituições que já mantêm o hábito salutar de informar o corpo discente sobre tais particularidades.

Recomenda-se, ainda, que as IES mantenham nas páginas de acesso ao ambiente virtual, a indicação de qual é o AVA utilizado e quais os parceiros envolvidos no compartilhamento de informações, mesmo que seja para simples divulgação, vinculando tais recursos àqueles pequenos ícones de comunicação visual para o aluno reconhecer o que será, efetivamente, utilizado na prática do processo pedagógico.

Também indicamos que as IES usuárias de tecnologias próprias, preocupem-se em mostrar ao menos os links dos desenvolvedores com suas logomarcas, a simbologia de marca registrada e/ou copyright, para que não haja risco de ter o seu AVA copiado visualmente por pessoas não autorizadas e não tenham como comprovar a propriedade intelectual do desenvolvimento daquela tecnologia.

Com base na legislação atual, algumas perguntas identificadas durante a pesquisa ficam sem resposta, a exemplo da carga horária que compõe a grade curricular da modalidade EaD integral, semipresencial ou híbrida, pois caso o aluno tenha a obrigatoriedade de cumprir $400 \mathrm{~h}$ semestrais ou por módulos, dependendo da IES, como seria computada a carga horária das atividades propostas pelo tutor-docente no ambiente EaD? Como, especificamente em ADS, há IES que conseguem integralizar o curso em apenas dois anos na modalidade EaD? Possivelmente e em tese, as atividades a distância sejam flexibilizadas e a distribuição da carga horária entre os módulos cheguem a $500 \mathrm{~h} / \mathrm{semestre,} \mathrm{o} \mathrm{que} \mathrm{equivaleria} \mathrm{a} 5$ horas diárias em 100 dias letivos e, neste aspecto, questionamos: há legislação específica do MEC definindo tal situação? 


\section{CONSIDERAÇÕES FINAIS}

Dentre as recomendações indicadas aqui, a prioritária, em nosso ponto de vista, seria a correção imediata, por parte das instituições, da carga horária constante no e-MEC, com o que realmente o aluno está adquirindo ao assinar o contrato de prestação de serviço com a IES. Independente da modalidade de ensino, a IES tem o dever de indicar a grade curricular e a carga horária das disciplinas que serão integralizadas no decorrer do curso.

Outro fator essencial é que esta pesquisa está sendo desenvolvida numa perspectiva regional e nacional, a posteriori, identificando a relação entre carga horária disciplinar e a separação da matriz curricular entre os eixos de formação do curso de ADS. Finalmente, identificar o ambiente virtual utilizado na modalidade EaD ou semipresencial pelos alunos, pois, para a EaD o AVA é como se fosse as instalações de um curso presencial e, como analogia, deve-se permitir que o aluno ingressante visite todas as instalações que serão utilizadas durante o curso.

\section{REFERÊNCIAS}

BATISTA JR, Achiles Ferreira et al. Flipped Classroom em uma metodologia EaD híbrida: uma ação prática com 0 uso de redes sociais. Disponível em: <http://www.abed.org.br/congresso2017/trabalhos/pdf/48.pdf>. Acesso em: 26 abr. 2018.

BRASIL. Ministério da Educação (MEC). Catálogo Nacional de Cursos Superiores de Tecnologia. Brasília, DF: MEC, 2016. Disponível em: <http://portal.mec.gov.br/index.php ?option=com_docman\&view=download \&alias=44501-cncst-2016-3edcpdf\&category_slug=junho-2016-pdf\&Itemid=30192> . Acesso em: 17 abr. 2018.

Ministério da Educação (MEC). Diretrizes Curriculares: Cursos de Graduação. Brasília, DF: MEC, 2016a. Disponível em: <http://portal.mec.gov.br/ assessoria-internaci onal/apresentacao/323-secretarias-112877938/orgaos-

vinculados-82187207/12991-diretrizes-curriculares-cursos-de-graduacao>. Acesso em: 15 abr. 2018.

Ministério da Educação (MEC). Portaria Normativa № 40. Brasília, DF: MEC, 2007. Disponível em: <http://portal.mec.gov.br/index.php?option=com_docman\&view= download\&alias=16763-port-norm-040-2007-seres\&ltemid=30192>. Acesso em: 18 abr. 2018. 
CERVO, Amado L.; BERVIAN, Pedro A.; DA SILVA, Pedro. Metodologia Científica. 6. ed. São Paulo: Pearson Prentice Hall, 2007.

ESPÍNDOLA, Rafaela. Como aproveitar os $20 \%$ da carga horária de EAD com ensino semipresencial. Disponível em: <https://www.edools.com/semi presencial/>. Acesso em: 22 abr. 2018.

FREIRE, Paulo. Pedagogia do Oprimido. Rio de Janeiro: Paz e Terra, 2005.

GONÇALVES, Maria Helena Barreto et al. Referências para a educação profissional do Senac. SENAC. DN. Rio de Janeiro: SENAC/DFP/DI, 2002.

KOGUT, Luciano José et al. A importância das informações nos sites das Instituições de Ensino Superior quanto à Matriz Curricular e Perfil Profissional dos Cursos de Análise e Desenvolvimento de Sistemas. Revistalnformação \& Informação, Londrina, v. 23, n. 1, p. 172 - 203, jan./abr. 2018.

KOGUT, Luciano José; LIMA, Augusto Ferronato; CARMO, José Carlos Mariano do; NUNES, Leandro Pieper. Estudo comparativo dos cursos superiores de tecnologia em Análise e Desenvolvimento de Sistemas na Região Metropolitana de Florianópolis: estratégia de revisão para as modalidades de ensino a distância e presencial. In: Colóquio Internacional de Gestão Universitária (CIGU), 17, 2017, Universidade Nacional de Mar del Plata. Anais do XVII Colóquio Internacional de Gestão Universitária. Florianópolis: UFSC, 2017.

[1] Definição da Lei Complementar no 636 de 9 de setembro de 2014, Art. 1ํ, parágrafo $1{ }^{\circ}$, considerando a microrregião da Grande Florianópolis. ${ }^{[2]}$ Nomenclatura imposta pela Lei № 13.168 de 6 de outubro de 2015, sendo que algumas IES não utilizam tal definição em seus portais institucionais, mencionando matriz curricular ou estrutura curricular como sinônimos. 